
\title{
25 Research Soure \\ Distribution of 31 endocrine disrupting compounds in the Taihu Lake and application of the fish plasma model
}

\section{Yifan Bao}

Tongji University College of Environmental Science and Engineering

\section{Wenping Huang}

Tongji University College of Environmental Science and Engineering

Hu Xialin ( $\nabla$ xlhu@tongji.edu.cn)

Tongji University College of Environmental Science and Engineering https://orcid.org/0000-0003-08970741

\section{Daqiang Yin}

Tongji University College of Environmental Science and Engineering

\section{Research}

Keywords: Endocrine disrupting compounds, Water, Wild fish, Plasma, Fish plasma model, Field

Posted Date: February 17th, 2020

DOI: https://doi.org/10.21203/rs.2.23622/v1

License: (c) (i) This work is licensed under a Creative Commons Attribution 4.0 International License. Read Full License

Version of Record: A version of this preprint was published at Environmental Sciences Europe on May 24th, 2020. See the published version at https://doi.org/10.1186/s12302-020-00347-0. 


\section{Abstract}

Background: The successful application of Fish plasma model (FPM) will greatly simplify the risk assessment of drugs. At present, the FPM has been applied to the risk assessment of several human drugs with high hydrophobicity. However, its applicability to a wide variety of compounds needs to be tested. Filed work about distribution characteristics of endocrine disrupting compounds (EDCs) in water and in fish plasma plays a key role in promoting the successful application of FPM. However, there are few reports on the distribution of EDCs in fish, especially in wild fish plasma.

Results: The distribution of 31 EDCs, including seven estrogens, eight androgens, six progesterones, five glucocorticoids and five industrial compounds, in water and in plasma of five categories of wild fishes in Taihu Lake was studied and the typical FPM was tested by the field data. The detected concentration of most compounds is relatively low $(<10 \mathrm{ng} / \mathrm{L})$, and the industrial compounds are the predominant pollutants with the highest concentration up to $291.7 \mathrm{ng} / \mathrm{L}$ (Bisphenol A) in water. In general, glucocorticoids were detected at highest concentrations in plasma of all kinds of fishes, followed by industrial compounds and estrogens. Except for glucocorticoids (up to 43.61 for Cortisone), the average concentrations of other four categories of EDCs in fish plasma were generally low ( $<10 \mu \mathrm{g} / \mathrm{L}$ ). The available measured bioaccumulation factors (BAFs) of 20 kinds of EDCs were in the range of 0 to 5626 . The bioaccumulation of EDCs in fish plasma is not only hydrophobicity dependent, and it is both fish species-specific and compound-dependent. The classical FPM was tested and the results indicated that the good coincide of measured logBAFs and the theoretical logBCFs was only observed for limited EDCs (7 out of 20). The present available FPM generally underestimated the LogBAFs of most hydrophilic EDCs (logKow $<3.87,11$ out of 20) whereas overestimated the LogBAFs of several high hydrophobic EDCs (LogKow >3.87) in fish plasma.

Conclusion区Although the present FPM is barely satisfactory, it is still promising for predicating the accumulation of EDCs in fish plasma and for further environmental risk assessment.

\section{Background}

Endocrine disrupting Chemicals (EDCs) are a new type of contaminant that can interfere with the biological endocrine system and lead to potentially adverse ecotoxicological effects. A wide variety of EDCs are widely used, such as estrogens, androgens, progestogens, adrenocortical hormones and industrial chemicals. EDCs exist widely in the environment, most of them have strong polarity and good water solubility. Because the treatment process of sewage plant and drinking water plant can not completely remove them, EDCs can enter the surface water environment through surface runoff, sewage treatment plant discharge and other different ways. EDCs have been widely detected in the water environment in China [1-4] and other countries [5-7], with the detection level of several ng / L. Although the level of EDCs in the environment is low, long-term low dose exposure shows a negative impact on aquatic organisms [8], which has attracted widespread attention of the scientific community and the public [9]. EDCs can affect the development of reproductive system[10-11],long-term exposure to 
environmental concentrations of progesterone and norethisterone can affect the sex differentiation of zebrafish [12].

Taihu Lake, one of the five largest fresh water lakes in China, is one of the largest fishing areas in China, which provides abundant biological species resources and has a very important ecological service function. With the rapid development of economy, Taihu Lake is seriously polluted by several EDCs and pharmaceuticals. Several EDCs including E1, E2, E3 and BPA has been investigated in the Taihu Lake [2, 13-14], with the highest detected concentration up to $194 \mathrm{ng} / \mathrm{L}$ for BPA. It is utmost important to investigated the occurrence and distribution of multi-class EDCs in the Taihu lake. 17 EDCs including estrogens, androgens, adrenocortical hormones, progesterones and industrial compounds were detected in the northern Taihu Lake in a recent study[15]. The maximum detected concentrations of estrogens, androgens, progestogens, and adrenocortical hormones in the water samples were $6.02 \mathrm{ng} / \mathrm{L}, 3.11 \mathrm{ng} / \mathrm{L}$, $1.01 \mathrm{ng} / \mathrm{L}$, and $20.82 \mathrm{ng} / \mathrm{L}$, respectively. BPA, BPS, and BPF were the most frequently detected chemicals, with the highest maximum concentration of $147.55 \mathrm{ng} / \mathrm{L}$ for BPA. However, current work only focuses on the northern Taihu Lake, and the seasonal variation and spatial distribution of EDCs in the Taihu Lake need further research.

Fish as a representative of aquatic organisms, accounted for an important position in the potential ecological risk assessment of pollutants. Fish plasma model (FPM) [16] as a risk assessment tool, uses existing mammalian pharmacology and toxicological data to predict the environmental risk of drugs, including some EDCs. According to the model [16], when a drug accumulates to a certain level in plasma, it will affect a target of human, such as receptor or enzyme, and then produce pharmacological or toxicological effects. Studies [17] have shown that $86 \%$ of the targets (receptors, enzymes) of human drugs are conservative in fish, so drugs of the same concentration level will also affect another species (fish) with the same target. According to the read-across hypothesis and the fish plasma model, the closer the concentration of human drugs in the plasma of non-targeted organisms is to that of human therapeutic plasma, the greater the potential risk of drugs to organisms [18]. Since the fish plasma model was proposed, it has been gradually used to assess the environmental risk of drugs [19-20]. It is very important to determine the concentration of pollutants in fish plasma for elucidating the toxic mechanism of drugs and evaluating the environmental risk of drugs. Rumi et al.[20] have shown that the determination of human drug concentration in fish plasma is of great significance in assessing the risk of human drugs to wild fish. The successful application of fish plasma model will greatly simplify the risk assessment of drugs. At present, the model has been successfully applied to the risk assessment of several human drugs, but it is only applicable to the pollutants with strong hydrophobicity, and its applicability to the ionizable pollutants needs to be tested.

Obtaining fish plasma concentrations of EDCs is the key to study and use fish plasma model for risk assessment. The concentration of EDCs in fish plasma can be predicted based on the concentration detected in water by studying the plasma water partition coefficient $\left(\mathrm{BCF}_{\text {plasma }}\right)$ of EDCs. Therefore, it is of great significance to study the EDC concentration in fish plasma and determine BCF [21]. Yu et al.[22] determined 13 pharmaceuticals and EDCs in fish plasma, of which the average concentration of estrone 
was $4.63 \mathrm{ng} / \mathrm{ml}$. Steele et al. [21] exposed 12 juvenile carp to medroxyprogesterone acetate aqueous solution with concentration of $100 \mu \mathrm{g} / \mathrm{L}$ for 7 days, and determined the concentration of medroxyprogesterone acetate in plasma (160.0-1549.3 $\mu \mathrm{g} / \mathrm{L})$ by LC-MS analysis method, with an average content of $1047.4 \mu \mathrm{g} / \mathrm{L}$, which is 4 times higher than the predicted value $(256 \mu \mathrm{g} / \mathrm{L})$ by fish plasma model [16]. In addition, the BCF value of medroxyprogesterone acetate in plasma was 13, which indicated that the bioaccumulation ability of medroxyprogesterone acetate in carp was weak. The results of this study provide a partial framework for predicting the ecological risks of human health and medroxyprogesterone acetate. However, most of the existing plasma studies are laboratory exposure studies, and there are few plasma data of wild fish. The extensive application of fish plasma model needs further field validation. Distribution of EDCs in wild fish plasma plays a key role in promoting the successful application of fish plasma model. However, there are few reports on the distribution of EDCs in fish plasma, especially in wild fish plasma.

This paper investigated the seasonal variation and spatial distribution of 31 EDCs in the Taihu Lake, including seven estrogens, eight androgens, six progesterones, five glucocorticoids and five industrial compounds. The distribution characteristics of EDCs in the plasma of five kinds of dominate wild fishes in the Taihu lake were also investigated. The popular fish plasma model was tested by the data of wild fish plasma of Taihu Lake. Our work provide valuable data of the wild fish plasma, which promote the further application of the fish plasma model in risk assessment.

\section{Methods}

\section{Chemicals and standards}

The chemicals used in the present study are provided in the Additional files. The information of abbreviation, CAS, molecular weight, structural formula of the 31 selected EDCs can be seen in Table S1. The analytes included seven estrogens, eight androgens, six progesterones, five adrenocortical hormones and five industrial compounds.

\section{Sampling}

Water

The sampling sites were set in several key districts in the northeastern part of Taihu Lake including mainly Wuxi Taihu and Suzhou Taihu (Fig. 1). A total of nine sampling sites were chosen, including three sites in the highly polluted Meiliang Bay of Wuxi (S1, S2 and S4), a site in Wuxi Zhushan bay (S3), a site in Wuxi Gong Bay (S5), and four sites in Suzhou Taihu (S6-S9). Two sampling events were conducted in June (wet season) and December (dry season), 2016. In June 2016, the rainfall was $385.9 \mathrm{~mm}$, and the average water level reached $4.01 \mathrm{~m}$. In December 2016, the rainfall was $50.7 \mathrm{~mm}$, and the average water level was $3.40 \mathrm{~m}$ (http://www.tba.gov.cn//tba/, in Chinese). The water samples ( $4 \mathrm{~L}$ per site) were collected with a clean stainless steel sampler, and the sampler and pre-cleaned brown bottles were 
washed three times with the target water sample. The samples were stored at $4{ }^{\circ} \mathrm{C}$ to prevent degradation. Water samples were extracted within $2 \mathrm{~d}$ from the time of collection.

Preferred position of Fig. 1

Fish

Carp (Cyprinus carpio) and crucian carp (Carassius auratus) are dominant species in Taihu Lake, while silver carp (Hypophthalmichthys molitrix), white stripe (sharpbell, Anabarilius) and spotted silver carp (bighead carp, Aristichthys nobilis ) are important economic species in Taihu Lake. In this study, these five representative wild fish species were caught and their plasma was collected to determine the EDC. On September 6, 2016, 38 wild fish were caught in the middle of Taihu Lake, the basic information of the fishes were shown in Table S2. After the laparotomy, blood was taken from the heart of the fish with a $1 \mathrm{ml}$ syringe. The collected blood samples are stored in a centrifuge tube with EDTA sodium salt in advance to prevent blood from clotting. The blood samples are centrifuged to collect the supernatant plasma. The plasma samples were stored at $-20^{\circ} \mathrm{C}$ before EDC analysis.

\section{Sample preparation and SPE}

Water

The water samples in triplicate ( $1 \mathrm{~L}$ each, adjust $\mathrm{pH}$ to 3.0 with formic acid) were spiked with internal standards at an absolute amount of $10 \mathrm{ng}$ prior to the solid phase extraction (SPE). SPE utilizing MCX SPE cartridges were performed on a Supelco (Madrid, Spain) vacuum manifold for 12 cartridges connected to a vacuum pump for the isolation and concentration of target EDCs. The cartridges were placed on a SPE element and conditioned sequentially with $6 \mathrm{~mL}$ of methanol and $6 \mathrm{~mL}$ of formic acid solution ( $\mathrm{pH}=3.0)$. Prior to the SPE, internal standards (10 $\mathrm{ng}$ each) were added into the aqueous samples. Then, samples were loaded through the cartridges at a flow rate of 2-2.5 mL-min-1. After all the samples were filtered, the cartridges were dried under nitrogen and cleaned sequentially with $6 \mathrm{~mL}$ of formic acid solution $(\mathrm{pH}=3.0)$. After that, the EDCs were eluted with $9 \mathrm{~mL}$ of $4.5 \%(\mathrm{~V}: \mathrm{V})$ ammonia/ acetonitrile solution. The extracts were dried under a gentle stream of nitrogen and redissolved in $0.5 \mathrm{~mL}$ of $35 \%(\mathrm{~V}: \mathrm{V})$ menthol/ water solution. Then the solutions were filtered through $0.22 \mu \mathrm{m}$ PTFE filter unit (Millex, Billerica, MA, USA) and prepared for analyzing with UPLC-MS/MS (Waters Xevo TQ MS, Milford, MA, USA) with the corresponding mobile phase.

Fish plasma

$1 \mathrm{~mL}$ of plasma was pipetted into a Teflon centrifuge tube, and $5 \mathrm{~mL}$ of acetonitrile was added to precipitate protein, then, $0.5 \mathrm{~mL}$ of internal standard with a concentration of $40 \mu \mathrm{g} / \mathrm{L}$ was added. The samples were mixed by vortexing, and then centrifuged at $9500 \mathrm{r} / \mathrm{min}$ for 15 minutes, finally, the supernatant was recovered in a glass centrifuge tube. The sample was dried with nitrogen, and then $1 \mathrm{~mL}$ of methanol was vortexed to dissolve the residue, $10 \mathrm{~mL}$ of formic acid aqueous solution $(\mathrm{pH}=3.0)$ was added and vortexed, and the solid phase extraction was the same as that of the water sample. The eluent 
was blown dry with nitrogen, made up to volume with $1 \mathrm{~mL}$ of methanol, and passed through a $0.22 \mu \mathrm{m}$ PTFE needle filter membrane, and tested on the instrument under optimized chromatography conditions.

\section{Analytical determination of EDCs}

Ultra-performance liquid chromatography tandemmass spectrometry (UPLC-MS/MS) analysis was performed using a Waters Xevo TQ MS Instrument Platform (Milford, MA, USA). The 31 EDCs were separated by a BEH C18 column. Details about the analytical method are shown in the Additional files ("Analytical determination of EDCs"). The measurement parameters and detection limits (LODs) for UPLCMS/MS are listed in Table S3, Table S4 (water) and Table S5 (fish plasma). For water analysis, 31 EDCs showed a good linear relationship ( $R 2 \geq 0.99$ ). The limit of detection was $0.01-3 \mathrm{ng} / \mathrm{L}$, and the recoveries of tap water and surface water were $61.2 \%$ to $150 \%$ (20 ng/L), 54.4-141\% (50 ng/L) and $51.6-127 \%$ (25 ng/L), 52.2-143\%(100 ng/L), RSD < 25\%. In the analysis method of fish plasma, the LOD was 0.0003 to $2 \mu \mathrm{g} / \mathrm{L}$ (Dexa, $10 \mu \mathrm{g} / \mathrm{L}$ ), and the recoveries were 58.6-137.4\% (E2-ben, 150\%). These analytical methods had high sensitivity, good precision and selectivity, fulfilled the requirements of EDCs detection in environmental samples.

\section{Fish plasma model}

The steady state plasma concentration of compounds in fish $\left(\mathrm{F}_{S S} \mathrm{PC}\right)$ can be calculated according to the concentration of the compounds in water and the physical and chemical properties of the compounds. The classical fish plasma model was proposed by Huggett et al.[16] as following:

$F_{S S} P C=E C \times P_{\text {Blood:Water }}(1)$

In the formula, EC is the concentration of a compound in water, $\mathrm{P}_{\text {Blood:Water }}$ is the distribution coefficient of the compounds in plasma and in water, also known as bioconcentration factor in plasma (BCF), $\mathrm{P}_{\text {Blood:Water }}$ can be calculated by formula (2).

$\log \mathrm{P}_{\text {Blood:Water }}=0.73 \times \log \mathrm{K}_{\mathrm{OW}}-0.88(2)$

In this model, compounds with strong lipophilicity (logKow) are more likely to enter the plasma of fish from the water phase. Therefore, the deficiency of the above model is that it is only applicable to the compounds with strong hydrophobicity, while it might show large deviation for compounds with strong ionization ability. At present, most studies are based on the fish plasma model (formula (1) and (2)) proposed by Huggett et al. [16] to calculate the FssPC. However, the above fish plasm model is problematic when it is used to calculate the FssPC of compounds with strong polarity. Considering the influence of $\mathrm{pH}$ on the compounds in plasma, Valentet al.[23] used Dow(conditional octanol-water partition coefficient)instead of Kow $\square$ octanol-water partition coefficient) $\square$ to calculate the plasma water partition coefficient $\mathrm{P}_{\text {Blood:Water }}$ log $\mathrm{P}_{\text {Blood:Water }}=0.73 \times \log \mathrm{D}_{\mathrm{OW}}-0.88$ of sertraline, and obtained the theoretical FssPC value of sertraline in plasma, which was in good agreement with the measured value ratio. Fu et al.[24]and Schreiber et al.[25] proposed to use the improved model to calculate $P_{\text {Blood:Water }}$ for substances with LogKow value between 1 and 6. 
$\log \mathrm{P}_{\text {Blood:Water }}=0.85 \times \log \mathrm{K}_{\mathrm{OW}}-0.7(3)$

\section{Results And Discussion}

\section{Occurrence, seasonal variation and spatial distribution of EDCs in the water of Taihu Lake}

\section{Detection frequencies and levels of concentrations}

Table 1 shows the average, median, maximum and minimal concentrations as well as detection frequencies of the 31 EDCs at all the nine sampling sites in both sampling events. Except four compounds including Epite, Corti, Prednl and Noreth were not detected in both summer and winter, other 27 compounds were detected at varied frequencies (11-100\%). A highest detection frequency of $100 \%$ is observed for three EDCs including DES, BPA and BPS in both June and December at all the nine sampling sites. This suggests the wide applications of these three EDCs in Taihu area. Nan-phen, TES-pro, E2-ben and BPF were detected at frequency of $100 \%$ in winter, and E2-ben and BPF were also detected at high frequency of $89 \%$ and $44 \%$ in summer. Four EDCs including TES-pro, Dexa, Predn, and Hexe were not detected in the wet season (summer) \however, higher detection frequencies of $100 \%, 11 \%, 44 \%$ and $89 \%$ were observed in the dry season (winter), respectively. In contrast, Tren and Norges were not detected in the dry season (winter), but higher detection frequencies in the range of $22 \%$ and $11 \%$ were observed in the wet season (summer). As for the categories of the EDCs, three out of five individual compounds and all seven estrogens were detected at high frequency in both June and December (44-100\%), except for OP and NP (11-22\%) and Hexe in Summer (0\%). Seven out of eight Androgens were detected at low frequencies (0-22\%, except $56 \%$ for Bold ) in summer; however, four out of eight androgens were detected at high frequencies in winter (44\%-100\%, Nan-phen and TES-pro $100 \%$; Me-TES $67 \%$ and TES $44 \%$ ). Five out of six progesterones were detected at low frequencies in both summer $(0-22 \%)$ and winter $(0-56 \%)$, whereas higher detection frequencies were observed for Proges ( $89 \%$ in winter and $56 \%$ in summer). In general, adrenocortical hormones were detected at the lowest frequencies. In summer, only one out of five adrenocortical hormones (Me-prednl) were detected ; in winter, low detection frequencies $(0 \%-44 \%)$ were also observed for four out of five adrenocortical hormones, and only a higher detection frequency was observed for Me-prednl (56\%). In general, the detection frequency of EDCs in Taihu Lake is higher in dry season than that in the wet season.

The highest concentrations of all 31 detected EDCs were typically below $10 \mathrm{ng} / \mathrm{L}$ in both summer and winter (Table 1), except five compounds including BPA (102.89 ng/L in summer; $291.70 \mathrm{ng} / \mathrm{L}$ in winter ), BPS (45.35 ng/L in summer; $230.45 \mathrm{ng} / \mathrm{L}$ in winter), BPF (7.44 ng/L in summer; $114.03 \mathrm{ng} / \mathrm{L}$ in winter), Me-prednl ( $14.3 \mathrm{ng} / \mathrm{L}$ in summer) and Nan-phen ( $13.78 \mathrm{ng} / \mathrm{L}$ in winter). In June, the average concentrations were in the range of 0.19 to $28.57 \mathrm{ng} / \mathrm{L}$, the median concentrations were in the range of 0.19 to $22.8 \mathrm{ng} / \mathrm{L}$, and the maximum concentration was $102.89 \mathrm{ng} / \mathrm{L}$ (BPA). The average concentrations were below $1 \mathrm{ng} / \mathrm{L}$ for estrogens (except E3), androgens (except Tren), progesterones, and adrenocortical hormones (except Me-prednl) in summer. In December, the average concentrations were in the range of 0.33 to $84.87 \mathrm{ng} / \mathrm{L}$, the median concentrations were in the range of 0.3 to $42.15 \mathrm{ng} / \mathrm{L}$, and the maximum 
concentration was $291.7 \mathrm{ng} / \mathrm{L}$ (BPA). BPA showed the highest average concentrations in both June and December (28.57 and $84.87 \mathrm{ng} / \mathrm{L}$, respectively ), followed by BPS (10.2 and $37.35 \mathrm{ng} / \mathrm{L}$, respectively ) and BPF (3.62 and $21.98 \mathrm{ng} / \mathrm{L}$, respectively). Progesterones showed low concentrations ( $<1 \mathrm{ng} / \mathrm{L}$ ) in both June and December. Individual compounds were predominant and the total concentrations accounted for $44 \%$ to $96 \%$ of all the five categories of EDCs in each sampling sites.

\section{Seasonal variation and spatial distribution}

\section{Preferred position of Figure 2}

It can be seen from Figure 2 that the total concentration of each type of EDCs in the water samples of each sampling point is higher in winter (1-20 times) than that in summer as a whole, except for the progesterones at S1 and S2, the glucocorticoids at S2 and S4, and the industrial substances at S8 and S9. The results show that the concentration of phenolics EDCs is affected by many factors with the changes of high and low water periods. Water flow pattern, industrial wastewater discharge, discharge source distance, dilution effect, temperature, production consumption and other factors will affect pollutant residues[26]. When the temperature increases, the activity of microorganisms in the water will also increase. Some of the biodegradable substances will be consumed by microorganism metabolism, resulting in the decrease of their concentration in the water [27] . In addition, in the wet season, affected by continuous rainfall and other factors, the water volume and flow rate of rivers and lakes are not stable, and the flow pattern changes greatly. In the wet season, aquatic plants in the water can absorb phenol at the same time. Based on the above factors, the concentration of EDCs in Taihu Lake water in summer is significantly lower than that in winter. However, in the dry season, there is less rainfall, the dilution effect of water flow in winter is weakened, the mobility of water flow is poor, and the flow pattern is relatively stable. Therefore, the concentration of pollutants in water in winter will increase relatively, which is the same as the conclusion of kin et al. [28] in the study of seasonal changes of alkylphenol in Seine River. The detected numbers of EDCs at each sampling point in winter and summer were compared, as shown in Figure S1. It can be seen that the number of EDCs detected at each sampling point in winter is higher than that in summer, which proves that the concentration of substances detected in low water period is higher than that in high water period on the whole.

Industrial compounds and estrogens are the main pollutants in surface water of Taihu Lake. BPA, BPS and BPF are the main detected substances of industrial compounds, and BPA > BPS > BPF. In winter, Taihu Lake is more seriously polluted by industrial compounds. The species and concentration of EDCs in different sampling points were different. Yan et al. [29] tested the EDCs in Taihu Lake water. The detection frequency of E2, E3 and BPA was 100\%. The concentration of EDCs in different spatial sampling points also varied greatly, which may be caused by the different hydrological conditions of the lake water in different periods. In the nine sampling points, the concentrations of four kinds of substances in the north of Taihu Lake (S1-S5) were higher than those in the East (s6-s9), no matter in summer or in winter. Further work including more sampling events would be required to give a definitive seasonality. 
For the spatial distribution, as a whole, the EDC concentrations in Wuxi Taihu Lake (North Taihu Lake, S1S5) is higher than that in the Suzhou Taihu Lake (East Taihu Lake, S6-S9), which is consistent with our previous drug research results [30]. S1, S2 and S3 sampling points are located in Meiliang Bay and Zhushan Bay of Wuxi, which are economically developed and have serious industrial pollution. Meiliang Bay and Zhushan Bay, as receiving water bodies, receive a large number of sewage from sewage treatment plants in surrounding towns and untreated domestic sewage [31]. Meiliang Bay has been polluted seriously over the years. The water quality of the lake is generally V-type or inferior V-type, and the water exchange is slow, basically in a semi closed state. There are many chemical plants along the main river flowing into Zhushan Bay (S3), about 26000 tons of BPA are put into use as raw materials or standby materials every year, and the industrial wastewater discharged into the river by the chemical plant can reach 23400000 tons every year. Liu et al. [13] measured the EDCs in the tributary water of Taihu Lake, and found that the concentration of industrial compounds detected in Caohe was the highest (1380 ng/ L), which increased the concentration of S1 after flowing into Taihu Lake. S4 is located near Lihu bridge. Lihu lake is the inner lake of Taihu Lake stretching into Wuxi. It is the closest to the downtown of Wuxi City among all sampling points. The surrounding population is dense. There are about 50 hospitals and clinics. The discharge of a large number of municipal wastewater and domestic sewage may be the main reason for the high concentration of EDCs in S4 point [32]. S5 is located in Gonghu Bay and at the entrance of Wangyu River. As shown in Figure 2, the total detected concentration of estrogen in $\mathrm{S} 5$ is relatively high ( $3.75 \mathrm{ng} / \mathrm{L}$ in summer and $11.9 \mathrm{ng} / \mathrm{L}$ in winter). Wangyu River is a project river of "diverting the river to the Taihu Lake". Liu et al. [33] measured the EDCs in the Yangtze River water of Nanjing section, and found that the concentration level of phenol EDCs in the Yangtze River water was higher than that in Taihu Lake. Hu et al. [34] Detected a high concentration of estrogen in the Yangtze River, which entered Taihu Lake with the branch water of the Yangtze River (S5), which may be one of the reasons for the high concentration of estrogen in S5 [34]. According to Jiang et al. [35], both the activity of estrogen and the concentration of estrogen in the Yangtze River water are at the forefront of China. S6 is close to Suzhou, where the population is dense and animal husbandry and aquaculture are prevalent. Therefore, there are more estrogens discharged, resulting in higher concentration of four kinds of EDCs except industrial compounds in winter. A small amount of estrogen and androgen were detected in S7, S8 and S9. S7 is close to the center of the lake, most of which are villages and scenic spots, with relatively less pollution. $\mathrm{S} 8$ is close to Xukou. Xukou town has a rapid economic development in recent years. At the same time, S8 is located at the Hukou of Xujiang river. There are many villages and fishing villages along the Xujiang river. Most of the discharged domestic sewage and aquaculture wastewater are directly discharged into the river, and finally into Taihu Lake. S9 are close to Wuqi farm, with developed aquaculture and untreated wastewater. The aquaculture wastewater is directly discharged into Taihu Lake, which results in the detection of estrogen and androgen concentrations in S7, S8 and S9. In a word, the spatial distribution of EDCs is affected by hydrology, population density, industrial wastewater discharge, aquaculture, and river diversion project.

Comparison of EDCs pollution level with domestic and foreign water environment 
The concentration of EDCs in the water phase of Taihu Lake was compared with that at home and abroad, see Table S5 for details. In general, the concentration of EDCs detected in Taihu Lake is relatively high in winter. The concentration range of 31 kinds of EDCs detected in Taihu Lake is 18.6-338.05 ng / L in winter and 16.22-112.69 ng / $\mathrm{L}$ in summer. In addition, BPA, BPS and BPF are the main EDCs detected in the water phase. The other two substances with relatively high detection frequency and concentration in Taihu Lake are estrogen (3.55-14.19 $\mathrm{ng} / \mathrm{L}$ ) and androgen (1.22-15.5 $\mathrm{ng} / \mathrm{L})$, respectively. Taking the BPA with the highest concentration (2.38-291.7 ng /L) detected in Taihu Lake as an example, which is lower than that in Yangtze River (Nanjing section) (nd-563 ng / L) [33], Pearl River (4-377 ng / L) [36], Liaohe River (12.3-755.6 ng / L) [37], slightly higher than that in Yellow River (12.5-171.5 ng / L) [38], and the same concentration level as Chaohu Lake (7.3-224.9 ng / L) [13]. Compared with foreign studies, it is lower than the concentration levels in Iberia (0.11-649 ng / L) and Singapore (nd-2470 ng / L) [5], and higher than those in Italy (nd-145) [39], Spain (6-126) [40] , Australia (4-59) [41], and Nigeria (not detected) [42]. It can be seen that BPA in surface water of Taihu Lake shows moderate pollution level. Compared with the detected concentrations of EDCs in surface water at home and abroad, the EDCs in Taihu Lake is in the moderate and low pollution level.

\section{Distribution characteristics of EDCs in plasma of wild fish}

\section{Concentration levels and detection frequencies of EDCs in wild fish plasma}

The detection concentration levels and detection frequencies of 31 EDCs in the plasma of five wild fishes was shown in Table 2. The detection frequencies of 31 EDCs in the plasma of five kinds of wild fish was between $0 \%$ and 100\%, 8 EDCs including 1 androgen (Tren), 3 glucocorticoids (Dexa, Prednl, and Prednl), 1 estrogen (E2), 1 progestogen (Me囚ace) and 2 industrial compounds (OP and NP) were not detected in all plasma samples, and the other 23 EDCs were detected in varying degrees. The total detection frequency $(n=20)$ of androgen was between $5 \%$ (Noreth) to $35 \%$ (Nortes), except for tren $(0 \%)$. For glucocorticoids, only Corti (100\%) and me - prednl (10\%) was detected. For estrogens, the detection frequency was between 5\% (Dieno) to 100\% (E2 Ben), except that E2 was not detected. For progesterones, except for Me -ACE (0\%), other compounds were detected in the range of $5 \%$ (TES $\unrhd$ pro) to $55 \%$ (hydrop). For industrial compounds, only BPA (45\%), BPS (40\%), BPF (20\%) were detected. In terms of the maximum detected concentration in plasma of Carp $(n=8)$ and silver carp $(n=5)$, except Corti $(43.61 \mu \mathrm{g} /$ $\mathrm{L}$ in Carp and $37.24 \mu \mathrm{g} / \mathrm{L}$ in silver carp), the highest detected concentration of other substances is no more than $10 \mu \mathrm{g} / \mathrm{L}$, and the lowest detected concentration of 25 EDCs is less than $1 \mu \mathrm{g} / \mathrm{L}$. The total concentrations of the five categories of EDCs varied, with the values of $17.31 \mu \mathrm{g} / \mathrm{L}$ (androgens), 10.55 $\mu \mathrm{g} / \mathrm{L}$ (progesterone) , $41.5 \mu \mathrm{g} / \mathrm{L}$ (estrogens), $37.6 \mu \mathrm{g} / \mathrm{L}$ (industrial compounds) and $351.15 \mu \mathrm{g} / \mathrm{L}$ (glucocorticoids), respectively. Compared the distribution of EDCs in the plasma of different kinds of wild fish, the detection frequencies of tes (63\%), nortes (63\%), and hydrop (75\%) in the plasma of carp was higher than that in the plasma of other four kinds of fish. The detection frequencies of Norges was $100 \%$ in the plasma of silver carp and $0 \%$ in the other four kinds of fish. The detection frequencies of industrial compounds (BPA, BPS) in carp, crucian carp, silver carp and plasma was higher, while that in silver carp 
was $0 \%$. The average concentration of EDCs $(10.15 \mu \mathrm{g} / \mathrm{L}$ to $27.53 \mu \mathrm{g} / \mathrm{L})$ in the plasma of five kinds of wild fish is not significantly different

It is worth noting that the detection frequency of E2-ben in plasma is $100 \%$, which is consistent with the detection of E2-ben in water phase. E2-ben is more easily enriched in organism due to its high LogKow value (5.47). BPF was detected in water with high concentration and frequency, but rarely in fish plasma. Yu et al. [22] determined the EDCs in the plasma of sea bass, and found that the concentration range of E1 was 2.98-7.52 $\mu \mathrm{g} / \mathrm{L}$, and the detection range of BPA was 1.18-6.21 $\mu \mathrm{g} / \mathrm{L}$, which was similar to the detection level of BPA in the plasma in this study. Eight of the 31 EDCs were natural hormones, including Epite, TES, Corti, E1, E2, E3, Hydrop and Proges. Corti as a natural glucocorticoid was detected in all plasma, and the concentration of Corti was very high, ranging from 1.59-43.61 $\mu \mathrm{g} / \mathrm{L}$. In addition, the detection frequency of Corti, Epite and Tes-pro in water was $0 \%$, but they were detected in fish plasma to different degrees, which may be due to the low content of this pollutant in water (lower than the detection limit of the instrument and cannot be quantified) and bioaccumulation of these compounds in fish. Also, because this kind of EDCs can be secreted and metabolized by a certain organ (adrenocortical fat) in vivo, the possibility of endogenous compounds cannot be excluded. In addition, the more frequent detection of Hydrop in all plasma samples may be related to it's a natural synthetized hormone in the fish.

\section{Preferred position of Table 2}

\section{Distribution of EDCs in plasma of different species of wild fish}

The distribution of five categories of EDCs in the plasma of five kinds of wild fishes in Taihu Lake is shown in Figure 3. Except for glucocorticoids, the concentrations of other four kinds of EDCs (Estrogens, androgens, progesterones and industrial compounds) in fish plasma were generally low $(<10 \mu \mathrm{g} / \mathrm{L})$. The detection level of androgens in carp plasma $(0.43-2.95 \mu \mathrm{g} / \mathrm{L})$ is generally higher than that in crucian carp and silver carp (0.13-0.6 $\mu \mathrm{g} / \mathrm{L})$, and the detection level of glucocorticoids in silver carp plasma is generally lower (1.59-21.44 $\mu \mathrm{g} / \mathrm{L}$ ) than that in other four kinds of fish. The concentrations of estrogens in the plasma of crucian carp and silver carp (0.3-10.58 $\mu \mathrm{g} / \mathrm{L}$ ) were higher than those of other kinds of fishes. The concentrations of progesterones in the plasma of spotted silver carp were slightly higher than those of other kinds of fish. The concentrations in the plasma of crucian carp and silver carp were comparable. The concentrations of industrial compounds in the plasma of crucian carp (0-7.19 $\mu \mathrm{g} / \mathrm{L})$, carp (0.5-9.6 $\mu \mathrm{g} / \mathrm{L})$, and silver carp (0.35-7.19 $\mu \mathrm{g} / \mathrm{L}$ ) were comparable, but not detected in the plasma of spotted silver carp. In general, except for glucocorticoids and progesterones, there were no significant difference of the concentrations among the varied fishes for androgens, estrogens, glucocorticoids and industrial compounds.

\section{Preferred position of Figure 3}

The total concentrations of each category of EDCs in the plasma of five kinds of wild fishes are shown in Fig.4. In general, glucocorticoids were detected at highest concentrations in all kinds of fishes, followed 
by industrial compounds and estrogens. The total concentrations of androgens in the plasma of carp range from 0.43 to $2.95 \mu \mathrm{g} / \mathrm{L}$, estrogen from 0.15 to $3.4 \mu \mathrm{g} / \mathrm{L}$, industrial compounds from 0.5 to $9.6 \mu$ $\mathrm{g} / \mathrm{L}$. The total concentrations of glucocorticoids in the plasma of silver carp range from 0.44 to $37.24 \mu$ $\mathrm{g} / \mathrm{L}$, estrogens from 0.3 to $10.58 \mu \mathrm{g} / \mathrm{L}$, and industrial compounds is $0.35-7.19 \mu \mathrm{g} / \mathrm{L}$. These differences may be due to the differences between carp and silver carp, including the physiological differences in the absorption, metabolism and elimination of pollutants. The result indicates that the distribution of EDCs in fish plasma is species-specific and compound-dependent.

\section{Preferred position of Figure 4}

\section{Bioaccumulation fators (BAFs) of EDCs in fish plasma}

The study of bioaccumulation is of great significance in clarifying the migration and transformation of substances in the ecosystem and evaluating the possible impact of pollutants on the environment. It provides a scientific basis for the determination of environmental capacity and environmental standards. At present, BAFs have been used to quantitatively describe bioaccumulation, which is defined as the ratio of target pollutant concentration in fish to concentration in water. In the EU risk assessment system, compounds with BAF > 2000 are considered to show bioaccumulation, while compounds with BAF > 5000 are considered to show high bioaccumulation [43-44]. In order to evaluate the bioaccumulation capacity of EDCs in fish plasma, the BAF value in fish plasma of each EDCs was calculated. However, 11 compounds neither detected in the water (Epite, Corti, Predn, Noreth) nor detected in the fishes (Tren, Dexa, Predn, Prednl, E2, Me-ace, OP and NP) were excluded for BAF calculation. For the undetected substances in serval water or fish samples, take half of the value of each self-inspection limit [20]. Table 3 shown the calculated average BAF values of 20 EDCs in five kinds of fish plasma.

\section{Preferred position of Table 3}

From Table 3, it can be seen that the measured BAF values of 20 kinds of EDCs varied (0-5626). Most of the measured BAF values of EDCs in the plasma of five kinds of fishes are comparable, and most of EDCs do not show bioaccumulation, no significant interspecific difference is observed, and no relationship with fish weight / body length is observed. This result is consistent with previous study [20] which investigated the absorption of human use drugs in the plasma of Carassius auratus (Crucian carp) and Cyprinus carpio (Carp). The highest mean BAF value was observed for E3 (575 to 5626, LogKow 2.45), flowed by TES (373 to 3093, LogKow 2.99), Norges (250 to 2460, LogKow 3.8), Hexe (625 to 1400 , LogKow 4.98), E2-ben (104 to 1572, LogKow 5.47), Hydrop (60 to 1390, LogKow 3.16) and Me-pro (1474 in Carb, LogKow 3.5). Only 3 compounds including E3, TES and Norges show bioaccumulation capacity (BAF>2000) in different kinds of fishes. The BAF value (5626) of E3 in crucian carp plasma is higher than that of the other four kinds of fishes, showing a high bioaccumulation. At the same time, E3 shows bioaccumulation in silver carp plasma (BAF 2632), while Norges only shows bioaccumulation (BAF 2460) in spotted silver carp plasma. The BAFs of 13 out of the 20 EDCs were below 1000, of which the lowest BAFs (<100) were observed for Nan-phen (LogKow 2.62), Proges (LogKow 3.87)), BPA (LogKow 3.32) and BPF (LogKow 2.97). The BAF of BPA in the plasma of crucian carp (45-116), carp (15-129), silver carp 
(19-23) and white streaked carp (44) was found to be comparable, which is consistent with the results of Liu et al. [45] in the bioaccumulation of BPA in wild carp (29) and wild crucian carp (18) in Dianchi Lake. However, the BAF value of BPA in our study is slightly higher than that of crucian carp and carp in Dianchi Lake, which also reflects the difference of water quality between Taihu Lake and Dianchi Lake. At the same time, the lower BAF value indicates that the bioaccumulation ability of BPA in fish is weak, which is also reflected in other fish (medaka 20-68, rainbow trout 1.7-38.4) [46-47]. As shown in Figure 5(a), the overall trend of measured logBAF increased linearly with the increase of LogKow values of EDCs, although the linear correlation is not significant $\left(P>0.05, R^{2}=0.0428\right.$ to 0.1520$)$. This result indicated that the bioaccumulation of EDCs in fish plasma is not only hydrophobicity dependent. The bioaccumulation of EDCs in fish plasm is both fish species-specific and compound dependent, which is consistent with previous work[45]. Further work considering the tissue distribution and metabolism of the EDCs in the fish should be conducted.

\section{Preferred position of Figure 5}

\section{Application of the fish-plasma model}

The classical fish plasma model (formula (2)) proposed by Huggett et al. [16] and the improved model (formula (3)) proposed by Fu et al .[24] and Schreiber et al.[25] were tested, and the $P_{\text {Blood:Water, i.e. the }}$ theoretical BCF value, was calculated and compared with the measured BAF value. The theoretical BCF values and average measured BAF values of 20 EDCs (other 11 EDCs indulging Epite, Corti, Predn, Noret, Tren, Dexa, Predn, E2, Me-ace, OP and NP were neither detected in the water or in the fish were emitted for the calculation) in five kinds of fish plasma were shown in Table 3. It is found that the theoretical BCFs calculated by the classical FPM (Formula 2, $\mathrm{BCF}_{0}$ ) are close to the measured BAFs for seven EDCs, including Nan-phen (LogKow 2.62), ME-TES(LogKow 3.61), E2-ben(LogKow 5.47), DES(LogKow 5.07), Hexe(LogKow 4.98), BPA(LogKow 3.32), and BPS(LogKow 2.91). In general, both the classical FPM and the improved FPM underestimate the BAFs of 11 EDCs, including TES (LogKow 2.99), Bold(LogKow 3.0), Nortes (LogKow 2.78), TES-pro (LogKow 2.97), Me-prednl (LogKow 1.5), E1(LogKow 3.13), E3(LogKow 2.45), Me-pro(LogKow 3.5), Hydrop (LogKow 3.16), Norges (LogKow 3.8) and BPF (LogKow 2.91). The BAFs of E2-ben『LogKow 4.98『and Dieno (LogKow 5.9) were overestimated by the classical FPM, whereas the BAFs of five EDCs including E2-ben囚LogKow 4.98), Dieno (LogKow 5.9), DES (LogKow 5.07), Hexe (LogKow 4.98), proges (LogKow 3.87) were overestimated by the improved FPM. This results suggested it should be carefully to use the FPM models, since it either underestimated the BAFs of hydrophilic EDCs $\left(\log \mathrm{K}_{\mathrm{OW}}<3.87\right.$ ) or overestimated the BAFs of high hydrophobic EDcs (LogKow >3.87) in fish plasma. The relationship between measured logBAF and the theoretical logBCF calculated by the FPM are clearly displayed in Figure 5(b) and Figure 5 (c). The overall trend was that the measured logBAF increased with the increasing of the theoretical $\log B C F$, although the linearity was not significant $(P$ $>0.05$ ). From the 1:1 line in Figure 5(b) and Figure 5(c), we can conclude that the FPM underestimate the LogBAFs of most hydrophilic EDCs (logKow <3.87) and overestimated the LogBAFs of several high hydrophobic EDcs (LogKow >3.87) in fish plasma. The good coincide of measured logBAF and the theoretical $\operatorname{logBCF}$ are only observed for limited EDCs. Compared with the classical FPM and the 
improved FPM, the former model seems superior to the latter which greatly overestimated the BAFs of high hydrophobic EDCs (LogKow >3.87). In general, although the present FPM is barely satisfactory, it is still promising for predicating the accumulation of EDCs in fish plasma and for further environmental risk assessment.

Fish plasma model is a risk assessment tool that can quickly screen out priority control pollutants. Based on the ratio of the therapeutic effect data of the existing drugs in mammalian plasma to the theoretical data of fish plasma predicted by the model, the effect ratio (ER) can be calculated, and the environmental risk of the drugs can be quickly determined according to the value of ER. Therefore, the establishment of a prediction model suitable for a variety of pollutants is the key to promote the risk assessment work, and will greatly simplify the risk assessment work. However, at present, there is a lack of data on the treatment of EDCs in human plasma, and the model is only applicable to a few compounds. Its universality needs to be continuously verified, and a large number of plasma and field data are still needed to improve the existing fish plasma model.

\section{Conclusion}

In this study, the temporal and spatial distribution characteristics of 31 kinds of EDCs in Taihu Lake water were investigated. The detection frequency of industrial compounds $(22 \%-100 \%)$ and estrogens $(44 \%-$ $100 \%$ ) was higher. The detected concentration of most compounds is relatively low ( $<10 \mathrm{ng} / \mathrm{L}$ ), and the industrial compounds are the predominant pollutants with the highest concentration up to $291.7 \mathrm{ng} / \mathrm{L}$ (BPA). During the dry season in winter, the detection level of EDCs in Taihu Lake is higher than that in summer. The detection concentration of EDCs in the north of Taihu Lake is higher than that in the East. The spatial distribution of EDCs is affected by hydrology, population density, industrial wastewater discharge, aquaculture, and river diversion project.

The detection frequencies of 31 EDCs in the plasma of five kinds of wild fish was between $0 \%$ and $100 \%$, 8 EDCs including 1 androgen (Tren), 3 glucocorticoids (Dexa, Prednl, and Prednl), 1 estrogen (E2), 1 progestogen (Me-ace) and 2 industrial compounds (OP and NP) were not detected in all plasma samples. In general, glucocorticoids were detected at highest concentrations in all kinds of fishes, followed by industrial compounds and estrogens. Except for glucocorticoids (up to 43.61 for Corti), the average concentrations of other four categories of EDCs (Estrogens, androgens, progesterones and industrial compounds) in fish plasma were generally low $(<10 \mu \mathrm{g} / \mathrm{L})$. The bioaccumulation of EDCs in fish plasma is both fish species-specific and compound dependent. The measured BAF values of 20 kinds of EDCs were in the range of 0 to 5626. Most of the measured BAF values of EDCs in the plasma of five kinds of fishes are comparable, and most of EDCs do not show bioaccumulation (BAF < 20000), and no significant interspecific difference is observed. The overall trend of measured logBAF increased linearly with the increase of LogKow values of EDCs, although the linear correlation is not significant $\left(P>0.05, R^{2}\right.$ $=0.0428$ to 0.1520 ). This result indicated that the bioaccumulation of EDCs in fish plasma is not only hydrophobicity dependent. The FPM was tested and the results indicated that the good coincide of measured logBAF and the theoretical logBCF are only observed for limited EDCs. The present available 
FPM generally underestimated the LogBAFs of most hydrophilic EDCs (logKow $<3.87$ ) and overestimated the LogBAFs of several high hydrophobic EDcs (LogKow > 3.87) in fish plasma. In general, although the present FPM is barely satisfactory, it is still promising for predicating the accumulation of EDCs in fish plasma and for further environmental risk assessment.

In this study, the EDCs in the plasma of wild fish were determined, and some basic data were obtained. The existing fish plasma model was verified, but the data obtained was still insufficient. A large number of experiments and field data are still needed to verify and improve the fish plasma model. At the same time, $\mathrm{pH}$ is very important for the ionization of drugs. The improvement of the model should consider the important factor of $\mathrm{pH}$, and finally build the model in order to simplify the risk assessment of pollutants, improve the efficiency of assessment, and achieve the purpose of quickly screening out the priority control pollutants.

\section{Declarations}

\section{Abbreviations}

EDCs: Endocrine disrupting compounds; FPM: Fish plasma model; BAF: Bioaccumulation factor; BCF: Bioaccumulation factor; logKow: logarithms of Octanol-water partition coefficient; SPE: Solid phase extraction; UPLC-MS/MS: Ultra-performance liquid chromatography tandemmass spectrometry;

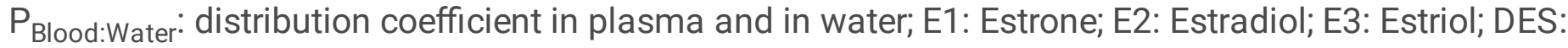
Diethyl-stilbestrol; Hexe: Hexestrol; E2-ben: Estradiol benzoate; Dieno: Dienoestrol; Nan-phen: Nandrolone Phenylpropionate; TES: Testosterone; Me-TES: Methyl-testosterone; Nortes: 19-Nortes-tosterone; Tren: Trenbolone; TES-pro: Testosterone propionate; Bold: Boldenone; Epite: Epitestosterone; Proges: Progesterone; Noreth: Norethisterone; Norges: DQ-】-Norgestrel; Me-pro: Medroxy Progesteron; Me-ace: Megestrol Acetate; Hydrop: Hydroxy progesterone; Predn: Prednisone; Corti: Cortisone; Dexa: Dexamethasone; Prednl: Prednisolone; Me-prednl: Methyl prednisolone; NP: 4-n-Nonyl Phenol; OP: 4-nOctyl Phenol; BPS: Bisphenol S; BPF: Bisphenol F; BPA: Bisphenol A.

\section{Authors' contributions}

Conceived and designed the experiments: Bao, Huang, Hu. Performed the experiments: Bao, Huang. Analyzed the data: Bao, Huang, Hu. Wrote the manuscript: Bao, Hu, Yin. All authors read and edited the manuscript and agree with its publication in a scientific journal. All authors read and approved the final manuscript.

\section{Acknowledgements}

The authors thank Taihu Lake Ecological Research Station for providing laboratory for fish dissection.

\section{Competing interests}

The authors declare that they have no competing interests. 
Availability of data and materials

All data generated or analyzed during this study are included in this published article [and its supplementary information files].

\section{Consent for publication}

Not applicable.

\section{Ethics approval and consent to participate}

Not applicable.

\section{Funding}

This study was funded by the National Natural Science Foundation of China [grant numbers 21577103, 21777122].

\section{References}

1. Liu, S., Ying, G. G., Zhao, J. L., Chen, F., Yang, B., Zhou, L. J., \& Lai, H. J. (2011). Trace analysis of 28 steroids in surface water, wastewater and sludge samples by rapid resolution liquid chromatographyelectrospray ionization tandem mass spectrometry. J Chromatogr A, 1218(10), 1367-1378. doi:10.1016/j.chroma.2011.01.014

2. Wang, Y., Wang, Q., Hu, L., Lu, G., \& Li, Y. (2015). Occurrence of estrogens in water, sediment and biota and their ecological risk in Northern Taihu Lake in China. Environ Geochem Health, 37(1), 147-156. doi:10.1007/s10653-014-9637-0

3. Huang, Y. Q., Wong, C. K., Zheng, J. S., Bouwman, H., Barra, R., Wahlström, B., Neretin, L., \& Wong, M. H. (2011). Bisphenol A (BPA) in China: a review of sources, environmental levels, and potential human health impacts. Environment International, 42(1), 91-99.

4. Chang, H., Hu, J., \& Shao, B. (2007). Occurrence of natural and synthetic glucocorticoids in sewage treatment plants and receiving river waters. Environ Sci Technol, 41(10), 3462-3468. doi:10.1021/es062746o

5. Gorga, M., Insa, S., Petrovic, M., \& Barcelo, D. (2015). Occurrence and spatial distribution of EDCs and related compounds in waters and sediments of Iberian rivers. Sci Total Environ, 503-504, 69-86. doi:10.1016/j.scitotenv.2014.06.037

6. Yamazaki, E., Yamashita, N., Taniyasu, S., Lam, J., Lam, P. K., Moon, H. B., Jeong, Y., Kannan, P., Achyuthan, H., Munuswamy, N., \& Kannan, K. (2015). Bisphenol A and other bisphenol analogues including BPS and BPF in surface water samples from Japan, China, Korea and India. Ecotoxicol Environ Saf, 122, 565-572. doi:10.1016/j.ecoenv.2015.09.029 
7. Isobe, T., Sato, K., Joon-Woo, K., Tanabe, S., Suzuki, G., \& Nakayama, K. (2015). Determination of natural and synthetic glucocorticoids in effluent of sewage treatment plants using ultrahigh performance liquid chromatography-tandem mass spectrometry. Environmental Science and Pollution Research, 22(18), 14127-14135. doi:10.1007/s11356-015-4626-0

8. Kolodziej, E. P., Gray, J. L., \& Sedlak, D. L. (2003). Quantification of steroid hormones with pheromonal properties in municipal wastewater effluent. Environ Toxicol Chem, 22(11), 2622-2629. doi:10.1897/03-42

9. Segner, H. (2006). Comment on "Lessons from endocrine disruption and their application to other issues concerning trace organics in the aquatic environment". Environmental Science \& Technology, 4O(3), 1084-1085. doi:10.1021/es051791d

10. Ottinger, M. A., Lavoie, E. T., Thompson, N., Bohannon, M., Dean, K., \& Jr., M. J. Q. Is the gonadotropin releasing hormone system vulnerable to endocrine disruption in birds? , 163(1-2), 104-108.

11. Patisaul, H. B., Todd, K. L., Mickens, J. A., \& Adewale, H. B. (2009). Impact of neonatal exposure to the ERa agonist PPT, bisphenol-A or phytoestrogens on hypothalamic kisspeptin fiber density in male and female rats. $30(3), 350-357$.

12. Liang, Y. Q., Huang, G. Y., Liu, S. S., Zhao, J. L., Yang, Y. Y., Chen, X. W., Tian, F., Jiang, Y. X., \& Ying, G. G. (2015). Long-term exposure to environmentally relevant concentrations of progesterone and norgestrel affects sex differentiation in zebrafish (Danio rerio). Aquat Toxicol, 160, 172-179. doi:10.1016/j.aquatox.2015.01.006

13. Liu, D., Liu, J., Guo, M., Xu, H., Zhang, S., Shi, L., \& Yao, C. (2016). Occurrence, distribution, and risk assessment of alkylphenols, bisphenol $A$, and tetrabromobisphenol $A$ in surface water, suspended particulate matter, and sediment in Taihu Lake and its tributaries. Mar Pollut Bull, 112(1-2), 142-150. doi:10.1016/j.marpolbul.2016.08.026

14. Yan, Z., Lu, G., Liu, J., \& Jin, S. (2012). An integrated assessment of estrogenic contamination and feminization risk in fish in Taihu Lake, China. Ecotoxicol Environ Saf, 84, 334-340. doi:10.1016/j.ecoenv.2012.08.010

15. Jia, Y. L., Monika, Hammers.W, Sarah, Crawford, Chen, Q. Q., \& Thomas.B. Effect-based and chemical analyses of agonistic and antagonistic endocrine disruptors in multiple matrices of eutrophic freshwaters.

16. Huggett, D. B., Cook, J. C., Ericson, J. F., \& Williams, R. T. (2003). A theoretical model for utilizing mammalian pharmacology and safety data to prioritize potential impacts of human pharmaceuticals to fish. Human and Ecological Risk Assessment, 9(7), 1789-1799. doi:10.1080/714044797

17. Gunnarsson, L., Jauhiainen, A., Kristiansson, E., Nerman, O., \& Larsson, D. G. J. (2008). Evolutionary conservation of human drug targets in organisms used for environmental risk assessments. Environmental Science \& Technology, 42(15), 5807-5813. doi:10.1021/es8005173

18. Rand-Weaver, M., Margiotta-Casaluci, L., Patel, A., Panter, G. H., Owen, S. F., \& Sumpter, J. P. (2013). The read-across hypothesis and environmental risk assessment of pharmaceuticals. Environ Sci 
Technol, 47(20), 11384-11395. doi:10.1021/es402065a

19. Brown, J. N., Paxeus, N., Forlin, L., \& Larsson, D. G. J. (2007). Variations in bioconcentration of human pharmaceuticals from sewage effluents into fish blood plasma. Environmental Toxicology and Pharmacology, 24(3), 267-274. doi:10.1016/j.etap.2007.06.005

20. Tanoue, R., Nomiyama, K., Nakamura, H., Kim, J. W., Isobe, T., Shinohara, R., Kunisue, T., \& Tanabe, S. (2015). Uptake and Tissue Distribution of Pharmaceuticals and Personal Care Products in Wild Fish from Treated-Wastewater-Impacted Streams. Environ Sci Technol, 49(19), 11649-11658. doi:10.1021/acs.est.5b02478

21. Steele, W. B. t., Garcia, S. N., Huggett, D. B., Venables, B. J., Barnes, S. E., 3rd, \& La Point, T. W. (2013). Tissue-specific bioconcentration of the synthetic steroid hormone medroxyprogesterone acetate in the common carp (Cyprinus carpio). Environ Toxicol Pharmacol, 36(3), 1120-1126. doi:10.1016/j.etap.2013.09.013

22. Yu, Y., \& Wu, L. S. (2015). Determination and occurrence of endocrine disrupting compounds, pharmaceuticals and personal care products in fish (Morone saxatilis). Frontiers of Environmental Science \& Engineering, 9(3), 475-481. doi:10.1007/s11783-014-0640-6

23. Jr, T. W. V., Gould, G. G., Berninger, J. P., Connors, K. A., Keele, N. B., Prosser, K. N., \& Brooks, B. W. (2012). Human Therapeutic Plasma Levels of the Selective Serotonin Reuptake Inhibitor (SSRI) Sertraline Decrease Serotonin Reuptake Transporter Binding and Shelter-Seeking Behavior in Adult Male Fathead Minnows. Environmental Science \& Technology, 46(4), 2427-2435.

24. Fu, W., Franco, A., \& Trapp, S. (2009). Methods for estimating the bioconcentration factor of ionizable organic chemicals. Environ Toxicol Chem, 28(7), 1372-1379. doi:10.1897/08-233.1

25. Schreiber, R., Gundel, U., Franz, S., Kuster, A., Rechenberg, B., \& Altenburger, R. (2011). Using the fish plasma model for comparative hazard identification for pharmaceuticals in the environment by extrapolation from human therapeutic data. Regulatory Toxicology and Pharmacology, 61(3), 261275. doi:10.1016/j.yrtph.2011.08.006

26. Quednow, K., \& Puttmann, W. (2008). Endocrine disruptors in freshwater streams of Hesse, Germany: changes in concentration levels in the time span from 2003 to 2005. Environ Pollut, 152(2), 476-483. doi:10.1016/j.envpol.2007.05.032

27. Jonkers, N., Laane, R. W. P. M., \& de Voogt, P. (2005). Sources and fate of nonylphenol ethoxylates and their metabolites in the Dutch coastal zone of the North Sea. Marine Chemistry, 96(1-2), 115-135. doi:10.1016/j.marchem.2004.12.004

28. Cailleaud, K., Budzinski, H., Souissi, S., \& Forgetleray, J. (2005). Seasonal variations of transfers of organic contaminants from the water column to a calanoid copepod, Eurytemora affinis : an in situ study of the Seine estuary.

29. Yan, Z., Lu, G., Liu, J., \& Jin, S. (2012). An integrated assessment of estrogenic contamination and feminization risk in fish in Taihu Lake, China. Ecotoxicology and Environmental Safety, 84(10), 334.

30. Hu, X. L., Bao, Y. F., Hu, J. J., Liu, Y. Y., \& Yin, D. Q. (2017). Occurrence of 25 pharmaceuticals in Taihu Lake and their removal from two urban drinking water treatment plants and a constructed wetland. 
Environmental Science and Pollution Research, 24(17), 14889-14902. doi:10.1007/s11356-017-8830y

31. Shen, J. H., Gutendorf, B., Vahl, H. H., Shen, L., \& Westendorf, J. (2001). Toxicological profile of pollutants in surface water from an area in Taihu Lake, Yangtze Delta. Toxicology, 166(1-2), 71-78. doi:10.1016/s0300-483x(01)00439-5

32. Zhang, Z., Ren, N., Kannan, K., Nan, J., Liu, L., Ma, W., Qi, H., \& Li, Y. (2014). Occurrence of endocrinedisrupting phenols and estrogens in water and sediment of the Songhua river, northeastern China. Arch Environ Contam Toxicol, 66(3), 361-369. doi:10.1007/s00244-014-9998-5

33. Liu, Y. H., Zhang, S. H., Ji, G. X., Wu, S. M., Guo, R. X., Cheng, J., Yan, Z. Y., \& Chen, J. Q. (2017). Occurrence, distribution and risk assessment of suspected endocrine-disrupting chemicals in surface water and suspended particulate matter of Yangtze River (Nanjing section). Ecotoxicol Environ Saf, 135, 90-97. doi:10.1016/j.ecoenv.2016.09.035

34. Hu, X., Shi, W., Cao, F., Hu, G., Hao, Y., Wei, S., Wang, X., \& Yu, H. (2013). Bioanalytical and instrumental analysis of estrogenic activities in drinking water sources from Yangtze River Delta. Chemosphere, 90(7), 2123-2128. doi:10.1016/j.chemosphere.2012.10.095

35. Jiang, W., Yan, Y., Ma, M., Wang, D., Luo, Q., Wang, Z., \& Satyanarayanan, S. K. (2012). Assessment of source water contamination by estrogenic disrupting compounds in China. J Environ Sci (China), 24(2), 320-328. doi:10.1016/s1001-0742(11)60746-8

36. Xu, W., Yan, W., Huang, W., Miao, L., \& Zhong, L. (2014). Endocrine-disrupting chemicals in the Pearl River Delta and coastal environment: sources, transfer, and implications. Environ Geochem Health, 36(6), 1095-1104. doi:10.1007/s10653-014-9618-3

37. Wang, L., Ying, G. G., Zhao, J. L., Liu, S., Yang, B., Zhou, L. J., Tao, R., \& Su, H. C. (2011). Assessing estrogenic activity in surface water and sediment of the Liao River system in northeast China using combined chemical and biological tools. Environmental Pollution, 159(1), 148-156. doi:10.1016/j.envpol.2010.09.017

38. Duan, X. Y., Li, Y. X., Li, X. G., Zhang, D. H., \& Gao, Y. (2014). Alkylphenols in surface sediments of the Yellow Sea and East China Sea inner shelf: occurrence, distribution and fate. Chemosphere, 107, 265273. doi:10.1016/j.chemosphere.2013.12.054

39. Pojana, G., Gomiero, A., Jonkers, N., \& Marcomini, A. (2007). Natural and synthetic endocrine disrupting compounds (EDCs) in water, sediment and biota of a coastal lagoon. Environ Int, 33(7), 929-936. doi:10.1016/j.envint.2007.05.003

40. Esteban, S., Gorga, M., Petrovic, M., Gonzalez-Alonso, S., Barcelo, D., \& Valcarcel, Y. (2014). Analysis and occurrence of endocrine-disrupting compounds and estrogenic activity in the surface waters of Central Spain. Sci Total Environ, 466-467, 939-951. doi:10.1016/j.scitotenv.2013.07.101

41. Ying, G. G., Kookana, R. S., Kumar, A., \& Mortimer, M. (2009). Occurrence and implications of estrogens and xenoestrogens in sewage effluents and receiving waters from South East Queensland. Sci Total Environ, 407(18), 5147-5155. doi:10.1016/j.scitotenv.2009.06.002 
42. Oketola, A. A., \& Fagbemigun, T. K. (2013). Determination of Nonylphenol, Octylphenol and Bisphenol-A in Water and Sediments of Two Major Rivers in Lagos, Nigeria. Journal of Environmental Protection, 4(7A), 38-45.

43. Leeuwen, K. V. (1996). Technical guidance document on risk assessment in support of commission directive $93 / 67 /$ EEC on risk assessment for new notified substances and commission regulation (EC) No1488/94 on risk assessment for existing substances Part II.

44. Arnot, J. A., \& Gobas, F. A. P. C. (2006). A review of bioconcentration factor (BCF) and bioaccumulation factor (BAF) assessments for organic chemicals in aquatic organisms. Environmental Reviews, 14(4), 257-297. doi:10.1139/A06-005

45. Liu, J., Wang, R., Huang, B., Lin, C., Wang, Y., \& Pan, X. (2011). Distribution and bioaccumulation of steroidal and phenolic endocrine disrupting chemicals in wild fish species from Dianchi Lake, China. Environ Pollut, 159(10), 2815-2822. doi:10.1016/j.envpol.2011.05.013

46. Lindholst, C., Pedersen, K. L., \& Pedersen, S. N. (2000). Estrogenic response of bisphenol A in rainbow trout (Oncorhynchus mykiss). Aquat Toxicol, 48(2-3), 87-94. doi:10.1016/s0166-445x(99)00051-x

47. Staples, C. A., Dorn, P. B., Klecka, G. M., O'Block, S. T., \& Harris, L. R. (1998). A review of the environmental fate, effects, and exposures of bisphenol A. Chemosphere, 36(10), 2149-2173. doi:10.1016/s0045-6535(97)10133-3

\section{Supplementary Files Legend}

Text. Chemicals and standards. Analytical determination of EDCs. Table S1. CAS, molecular weight, structural formula and logKow of the 31 selected EDCs. Table S2. Common names, Chinese name, scientific names, sampling number $(\mathrm{N})$, Length and weight of wild fish from the Taihu Lake. Table S3. MS parameters and retention time of 31 EDCs. Table S4. Linear range, correlation coefficients $\left(r^{2}\right)$, regression equations, LOQ of 31 EDCs and LODs in Water. Table S5. Linear range, correlation coefficients $\left(\mathrm{r}^{2}\right)$, regression equations, LOQ of 31 EDCs and LODs in fish plasma. Table S6. Comparison of EDC concentrations at home and abroad (ng/L). Figure S1. The number of detected EDCs in each sampling sites in summer and winter in the Taihu Lake.

\section{Tables}

Due to technical limitations, all tables are only available for download from the Supplementary Files section.

\section{Figures}




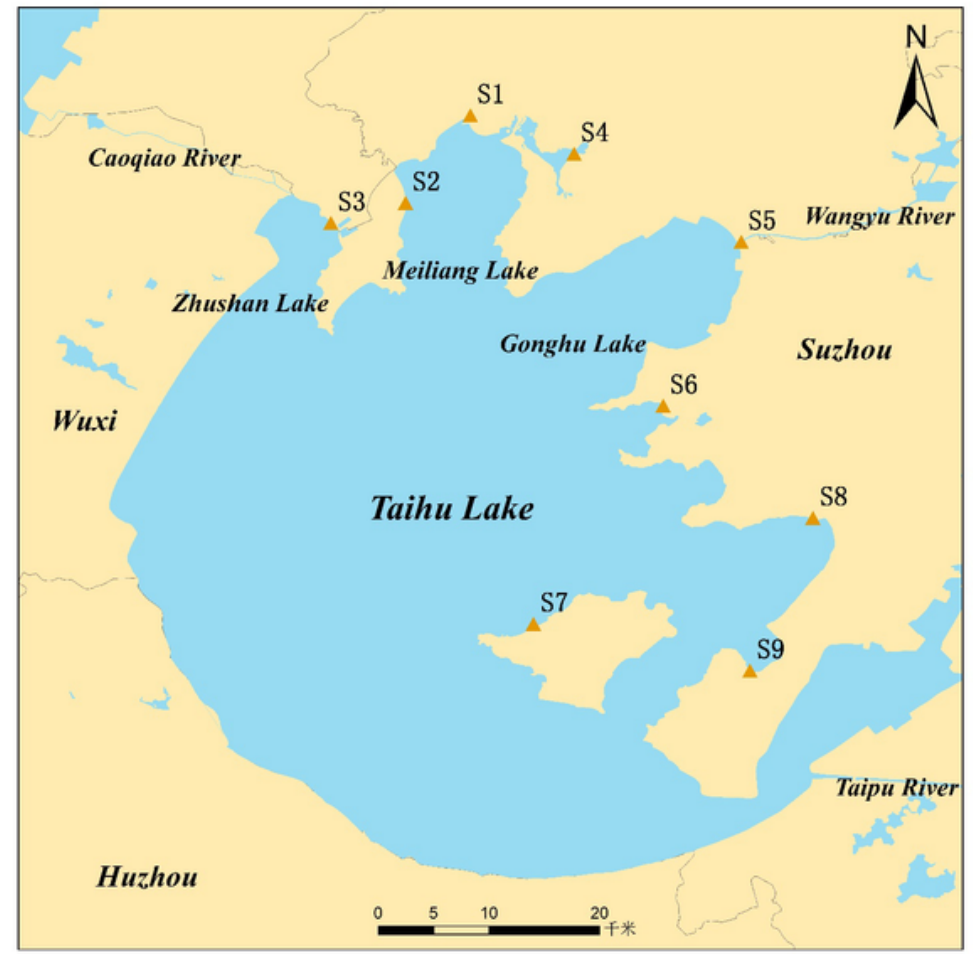

Figure 1. Sampling sites in the northeastern Taihu Lake. S1: Zhuiyuqiao; S2: Tianyuanqiao; S3:Hutoushan; S4: Lihudaqiao; S5: langshabang; S6: Xijingcun; S7: Yuwangmiao; S8: Xukoushuili; S9: dongshanhuhubinqiao

\section{Figure 1}

Sampling sites in the northeastern Taihu Lake. Note: The designations employed and the presentation of the material on this map do not imply the expression of any opinion whatsoever on the part of Research Square concerning the legal status of any country, territory, city or area or of its authorities, or concerning the delimitation of its frontiers or boundaries. This map has been provided by the authors. 


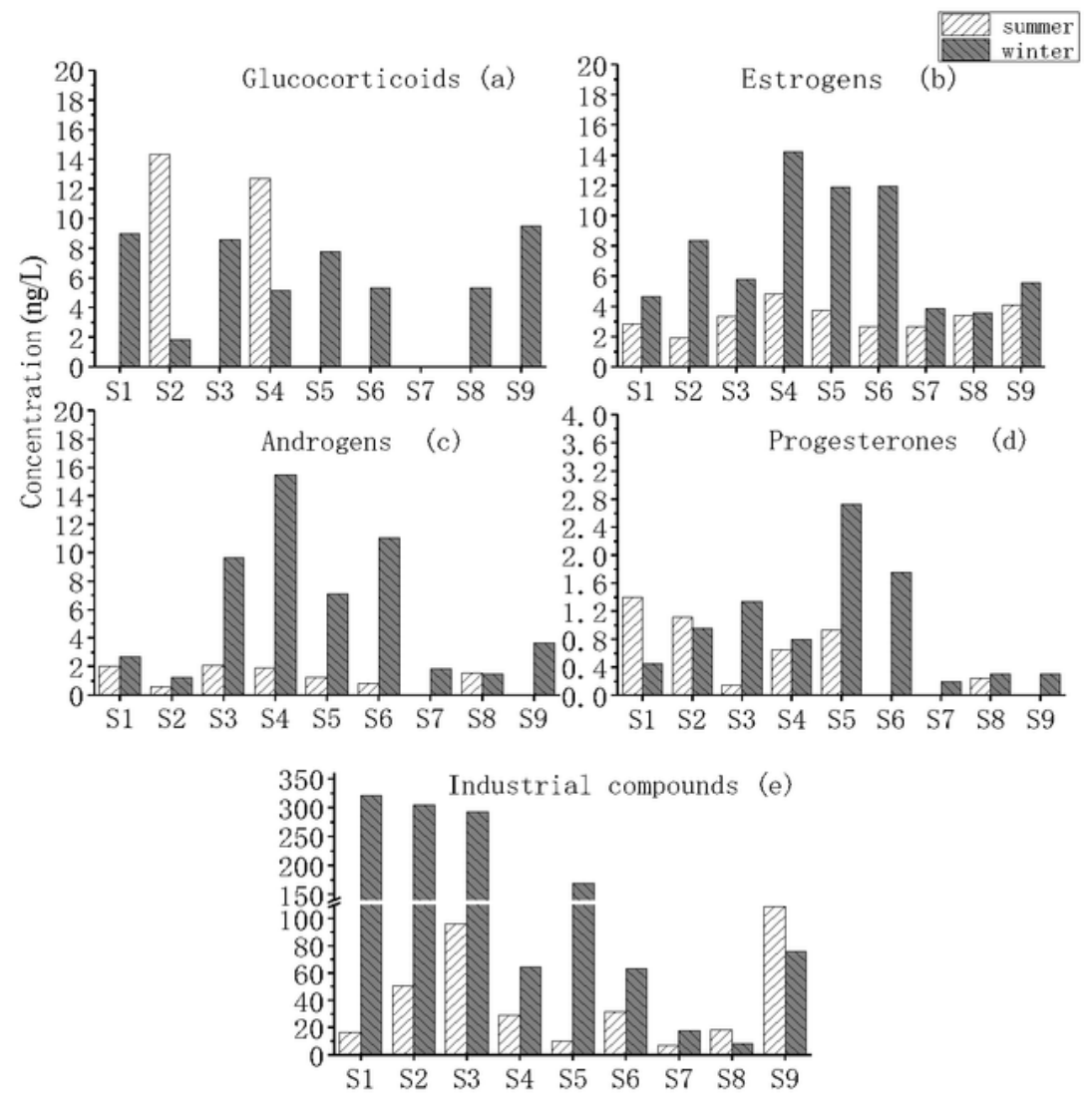

Figure 2. Total concentrations of five kinds of EDCs in the Taihu Lake in summer and in winter (a) glucocorticoids; (b) estrogens; (c) androgens; (d) progesterones; (e) industrial compounds.

Figure 2

Total concentrations of five kinds of EDCs in the Tai Lake in summer and in winter. 


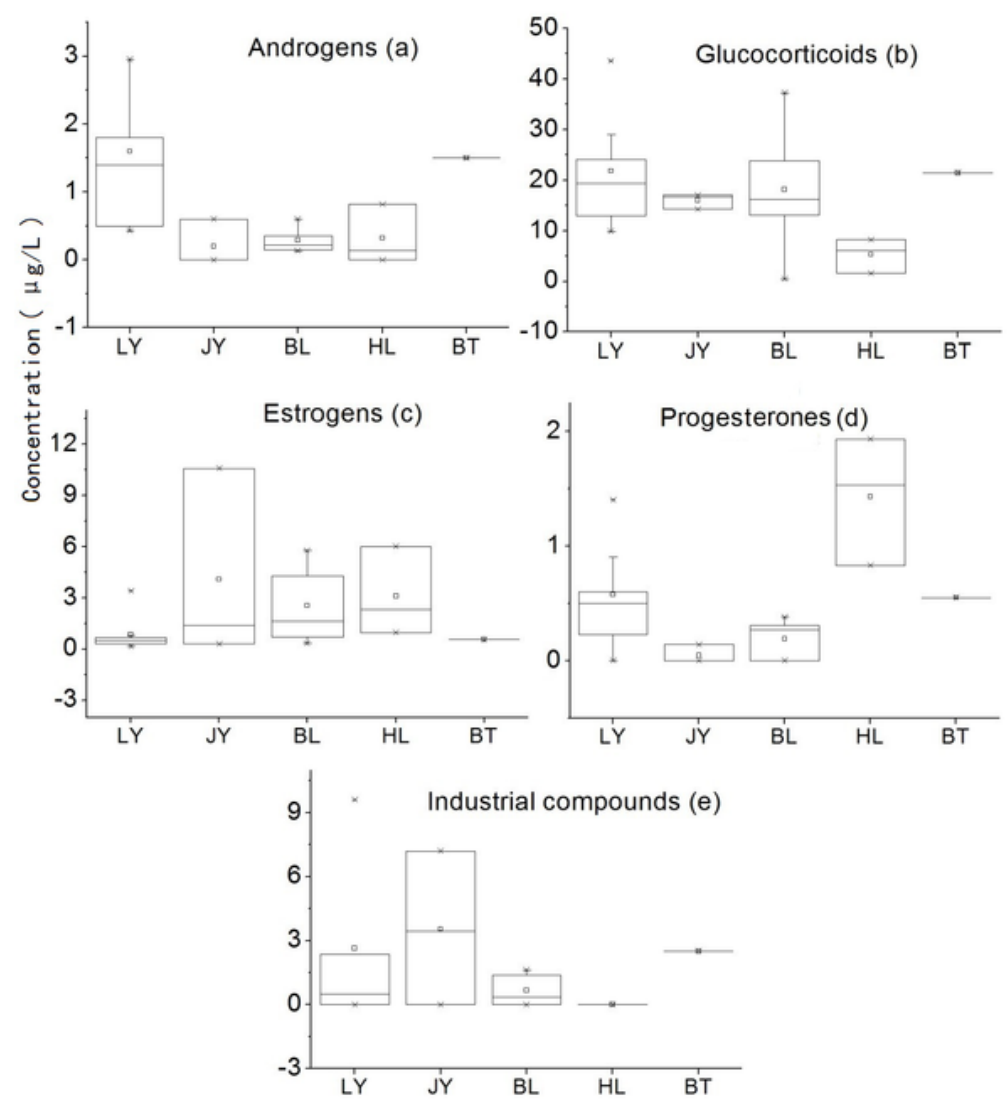

Figure 3. Distribution of the five kinds of EDCs in the plasmas of five wild fish species from the Taihu Lake. Each box represents 10th and 90 th percentile range of concentration.

(a) androgens; (b) glucocorticoid; (c) estrogens; (d) progesterones; (e) industrial compounds.

LY $($ Liyu $)=$ Carp; JY $($ Jiyu $)=$ Crucian carp; BL $($ Bailian $)=$ Silver carp;

BT $($ Baitiao $)=$ White stripe; $\mathrm{HL}($ Hualian $)=$ Spotted silver carp

\section{Figure 3}

Distribution of the five kinds of EDCs in the plasmas of five wild fish species from the Taihu Lake. 


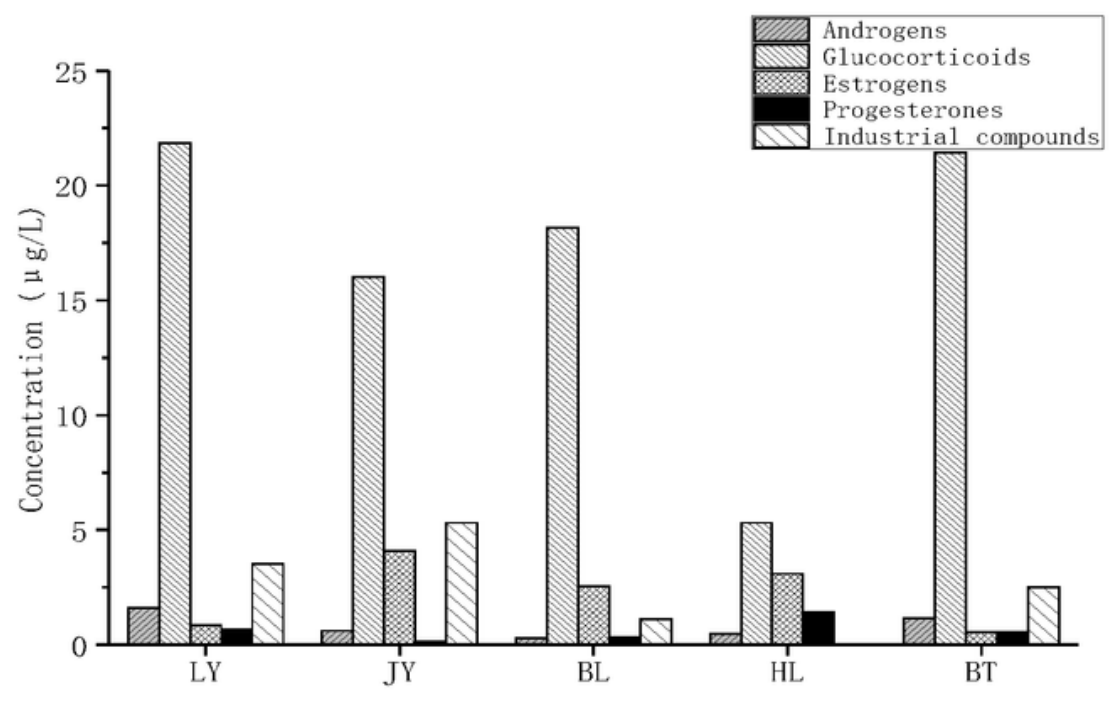

Figure 4. Total concentrations of the five kinds of EDCs in the plasmas of five wild fish species

from the Taihu Lake

LY $($ Liyu $)=$ Carp; JY $($ Jiyu $)=$ Crucian carp; BL $($ Bailian $)=$ Silver carp;

BT $($ Baitiao $)=$ White stripe HL $($ Hualian $)=$ Spotted silver carp

\section{Figure 4}

Total concentrations of the five kinds of EDCs in the plasmas of five wild fish species from the Taihu Lake. 
(a)

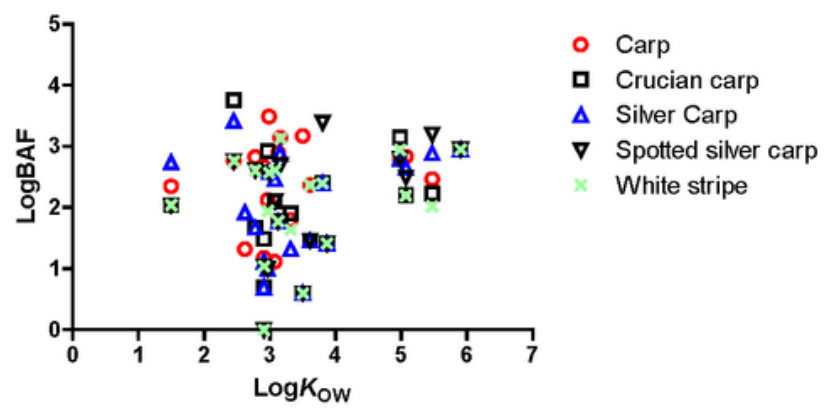

(b)

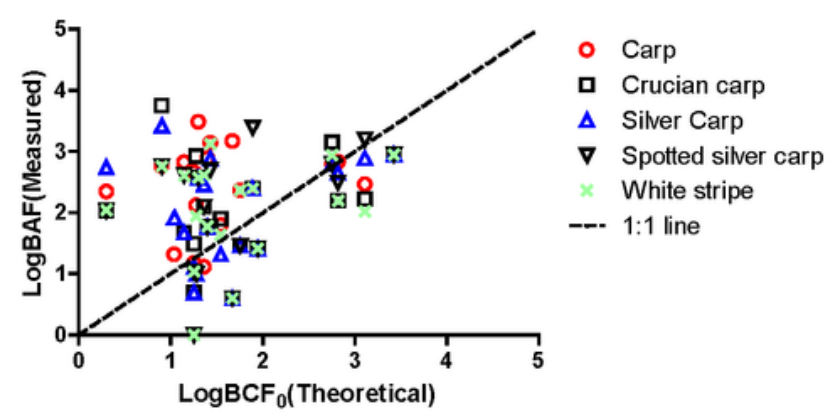

(c)

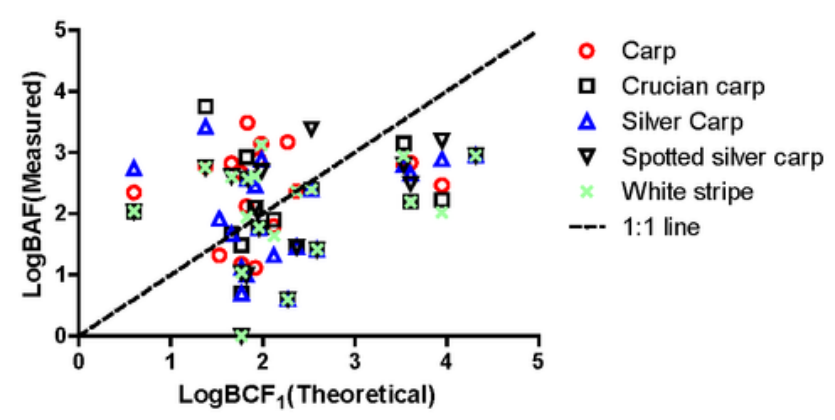

Figure 5. Relationship between measured $\log$ BAF in wild fish plasma with the Log Kow (a), the theoretical $\log \mathrm{BCF}_{0}$ (b) and the theoretical $\log \mathrm{BCF}_{1}$ (c) of $20 \mathrm{EDCs}$. $\log \mathrm{BCF}_{0}=0.73 \times \log \mathrm{K}_{\mathrm{ow}}$ 0.88 (formula 2 ); $\log \mathrm{BCF}_{1}=0.85 \times \log \mathrm{K}_{\mathrm{ow}}-0.7$ (formula 3 )

\section{Figure 5}

Relationship between measured logBAF in wild fish plasma with the LogKOW (a), the theoretical logBCF0 (b) and the theoretical logBCF1 (c) of 20 EDCs. $\log B C F 0=0.73 \times \log K O W-0.88$. (formula 2); logBCF1= $0.85 \times \operatorname{logKOW}-0.7$ (formula 3 ).

\section{Supplementary Files}


This is a list of supplementary files associated with this preprint. Click to download.

- Tables.docx

- Sl.docx 